PDFlib PLOP: PDF Linearization, Optimization, Protection

Page inserted by evaluation version www.pdflib.com - sales@pdflib.com 


\title{
An Evaluation of Otopathology in the MOV-13 Transgenic Mutant Mouse ${ }^{a}$
}

\author{
RICHARD A. ALTSCHULER, ${ }^{b, c}$ DAVID F. DOLAN,${ }^{b}$ \\ MARTIN PTOK, ${ }^{b}$ GANJEI GHOLIZADEH, ${ }^{b}$ \\ JEFFREY BONADIO, ${ }^{d}$ AND JOSEPH E. HAWKINS ${ }^{b}$ \\ ${ }^{b}$ Kresge Hearing Research Institute \\ ${ }^{c}$ Department of Anatomy and Cell Biology \\ ${ }^{d}$ Howard Hughes Medical Institute \\ University of Michigan \\ 1301 East Ann Street \\ Ann Arbor, Michigan 48109
}

Three major human osteopathological conditions are characterized by a serious impairment of hearing: otosclerosis, osteogenesis imperfecta tarda (OI), and Paget's disease. Some authors have even suggested that otosclerosis may represent a special case of OI. ${ }^{1,2}$ These diseases affect more than $1 \%$ of the adult population, ${ }^{3,4}$ but we still know too little about their causation and initial stages. One reason has been the lack of appropriate animal models, with the LP/J mouse the best now available for otosclerosis research. $^{5}$

A transgenic mutant mouse, MOV-13, has been developed by Jaenisch et al., ${ }^{6}$ in which the Moloney murine leukemia virus, inserted into the collagen gene, results in the loss of type I collagen in the homozygous mouse, and deficits in type I collagen in the heterozygous mouse. The heterozygous mouse has been proposed as a model for osteopathological disorders. ${ }^{7}$ We have therefore examined the temporal bones of this animal for signs of $\mathrm{OI}$ or otosclerosis, such as auditory deficits, spongeotic changes, and stapes ankylosis, and for possible cochlear abnormalities.

Auditory brain stem responses (ABR) were recorded from MOV-13 mice and control mice to obtain audiograms and response magnitude (input-output) functions. Tests were repeated weekly from 8 to 15 weeks of age at which time MOV-13 animals become leukemic. They were then heavily anesthetized and perfused through the heart with mixed aldehyde fixatives. Temporal bones were removed and the middle ear examined. The round window light reflex test was performed to assess stapes mobility. The temporal bone was oriented so as to observe light reflected from the round window membrane. Gentle pressure applied to the normal stapes causes an obvious change in this light reflex. Cochleae were then fixed by intrascalar perfusion, followed by decalcification and embedding in plastic. Sections through the stapes footplate, cochlea, and vestibule were cut, stained, and evaluated.

\section{ELECTROPHYSIOLOGY}

The heterozygous MOV-13 mouse showed a progressive hearing loss, with noticeable changes in sensitivity, beginning in the 10 th to 11 th week postpartum. The Inc.

${ }^{a}$ These studies were supported by the Research Fund of the American Otological Society, 
response magnitude function was suggestive of a mixed conductive and sensorineural impairment. FIGURE 1 shows audiograms for three MOV-13 mice at 8,11 , and 15 weeks post partum. In comparison with the control animals, the MOV-13 mice show a progressive decrease in sensitivity as a function of age.

\section{STAPES MOBILITY}

At 14 weeks, the results of the round window light reflex test ranged from positive (freely mobile stapes) to incompletely negative (partially fixed stapes). The results were well correlated with those of subsequent histological evaluations.

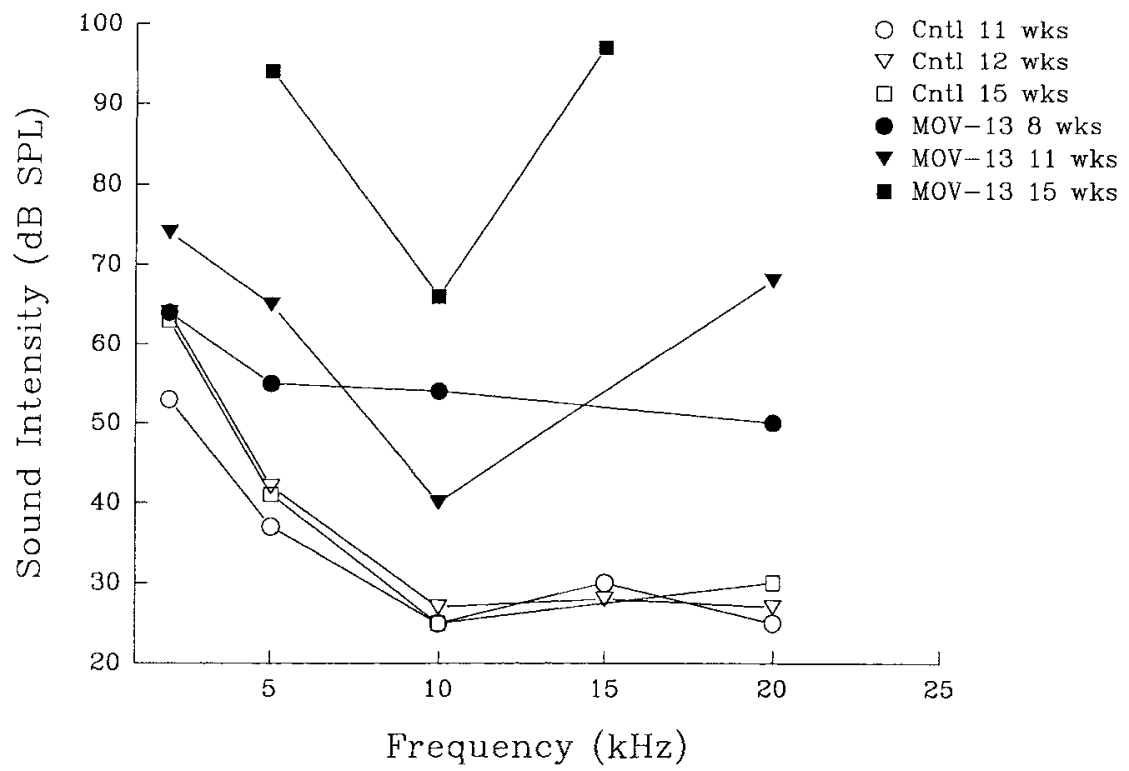

FIGURE 1. Audiograms from three MOV-13 mice at 8,11 , and 15 weeks postpartum (closed symbols) compared to three control animals (open symbols) at 8,12 , and 15 weeks. The MOV-13 show progressive elevations in sensitivity as a function of age, while controls show no changes. (From Bonadio et al. ${ }^{7}$ with permission.)

\section{HISTOLOGY}

New bone formation could often be observed grossly in the otic capsule. Sections through the cochlea showed varying degrees of hair cell loss, especially in the basal turn near the round window. In one ear, where an ingrowth of fibrous tissue was present on the tympanic side of the oval window, a partial fixation was evident at one end of the footplate (FIGURE 2a); at the other end the marginal ligament appeared unchanged. No focal spongeotic process was observed in the stapes or elsewhere. In another animal there was obvious thinning of the bone of the footplate (FIGURE 2b) as well as fibrosis near the stapes, but there was no evidence of footplate fixation (FIGURE 2b). No obvious changes were seen in the ampullar cristae or in the utricular and saccular maculae. 

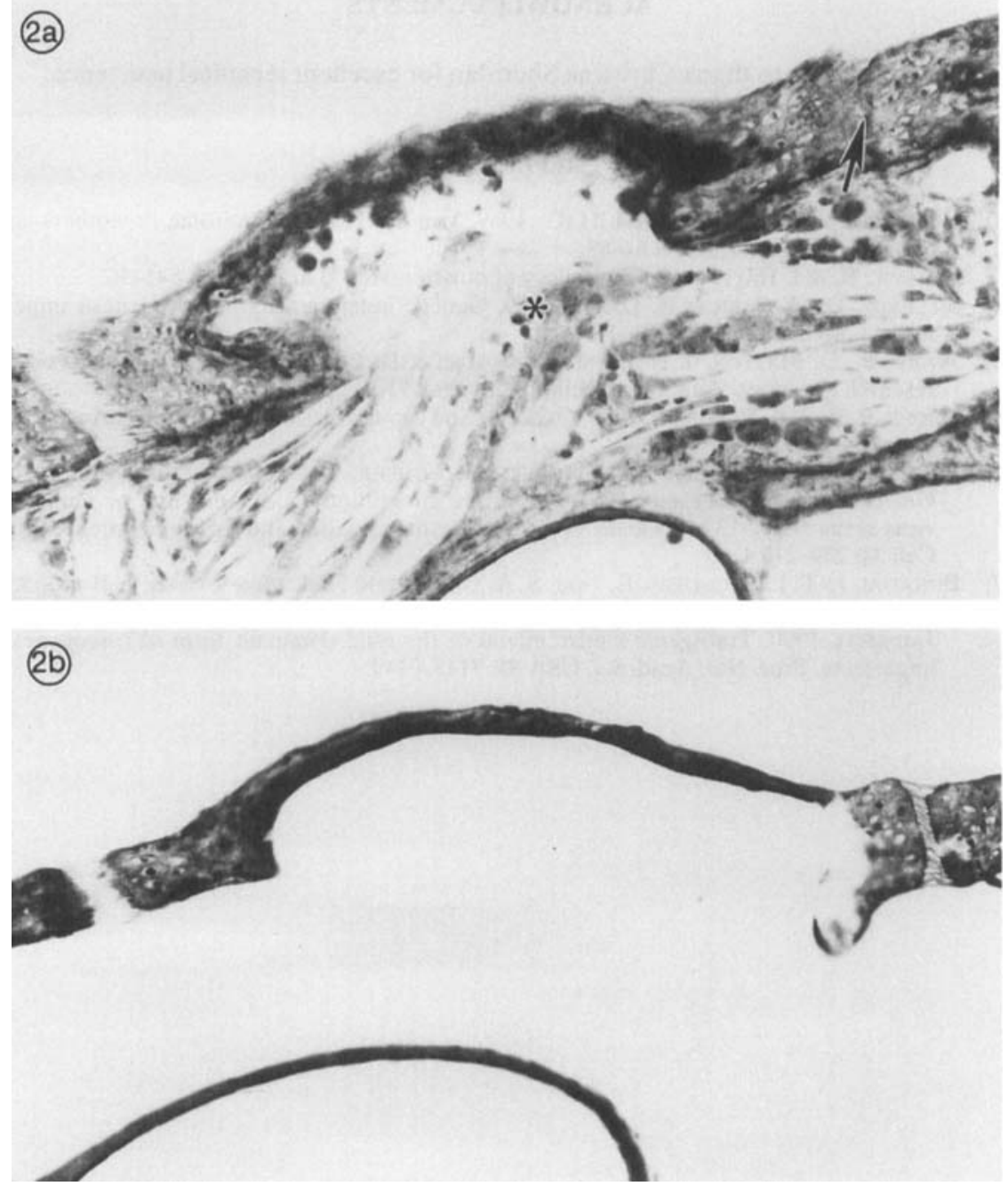

FIGURE 2. Six-micron plastic sections through the cochlea of 15 -week-old MOV-13 mice showing the footplate of the stapes by the oval window. Fibrosis (asterix) and fixation of the footplate (arrow) are seen in one cochlea (2a); thinning of the footplate is seen in another cochlea (2b).

From these preliminary observations it appears that the MOV-13 mouse may offer a useful model for the early changes in hearing that occur in osteogenesis imperfecta tarda, although the animal's limited life span probably excludes a complete development of the otopathologic process. The cochlear hair cell loss that accompanies the bony changes appears to have interesting implications as to the origin of the sensorineural deficit observed in human capsular (cochlear) otosclerosis. 


\section{ACKNOWLEDGMENTS}

We would like to thank Christine Sheridan for excellent technical assistance.

\section{REFERENCES}

1. Wullstein, H., R. Ogilvie \& I. Hall. 1969. Van der Hoeve's syndrome in mothers and daughters. J. Laryngol. 74: 64-83.

2. OGILVIE, R. \& I. HaLl. 1962. On etiology of otosclerosis. J. Laryngol. 76: 841-96.

3. Sillence, D., A. SENN \& D. DANKS. 1979. Genetic heterogeneity in osteogenesis imperfecta. J. Med. Genet. 16: 101-16.

4. Ward, P., D. Mattox, J. Hawkins, C. Krause \& D. Lim. 1982. Important unanswered research questions. Ann. Otol. Rhinol. Laryngol. 91(Suppl. 100): 11-14.

5. Chole, R. A. \& K. R. Henry. 1985. Ossicular and capuslar lesions in LP/J mice. Ann. Otol. Rhinol. Laryngol. 94: 366-372.

6. Jaenisch, R., K. Harbers, A. Schnieke, J. Lohler, I. Chumakov, D. Jahner, D. GROTKOPP \& E. HOFFMAN. 1983. Germ line integration of Moloney murine leukemia virus at the MOV-13 locus leads to recessive lethal mutation and early embryonic death. Cell 32: 209-216.

7. Bonadio, J., T. L. Saunders, E. Tsai, S. A. Goldstein, J. Morris-Wiman, L. Brinkley, D. F. Dolan, R. A. Altschuler, J. E. Hawkins, J. F. Bateman, T. Mascara \& R. JAENISCH. 1990. Transgenic mouse model of the mild dominant form of osteogenesis imperfecta. Proc. Nat. Acad. Sci. USA 87: 7145-7149. 